\title{
Development of a Semirigid Pavement Incorporating Ultrarapid Hardening Cement and Chemical Admixtures for Cement Grouts
}

\author{
Jin Wook Bang, ${ }^{1}$ Byung Jae Lee, ${ }^{2}$ and Yun Yong Kim ${ }^{3}$ \\ ${ }^{1}$ ReD Center, Tongyang Construction Materials Co., Ltd., No. 2822-1, Gimpo-dearo, Wolgot-myeon, Gimpo-si, \\ Gyeonggi-do 10024, Republic of Korea \\ ${ }^{2}$ R\&D Center, JNTINC Co., Ltd., No. 9, Hyundaikia-ro, 830 Beon-gil, Bibong-myeon, Hwaseong-City, \\ Gyeonggi-do 18284, Republic of Korea \\ ${ }^{3}$ Department of Civil Engineering, Chungnam National University, Daejeon 34134, Republic of Korea
}

Correspondence should be addressed to Yun Yong Kim; yunkim@cnu.ac.kr

Received 31 March 2017; Accepted 30 April 2017; Published 8 June 2017

Academic Editor: Xiao-Yong Wang

Copyright (C) 2017 Jin Wook Bang et al. This is an open access article distributed under the Creative Commons Attribution License, which permits unrestricted use, distribution, and reproduction in any medium, provided the original work is properly cited.

\begin{abstract}
Mechanical tests were carried out to evaluate the influence and effects of fluidity and compressive strength of cement grout on semirigid asphalt pavement. An open graded asphalt skeleton was designed in order to achieve target porosity in the range of $18 \sim 22 \%$. In addition, four types of cement grout mixtures were produced with varying mix proportions with ultrarapid hardening cement and chemical admixtures, that is, accelerating and retarding agents. For the semirigid pavement specimens, mechanical experiments to measure properties such as porosity, flexural strength, Marshall stability, and wheel tracking resistance were carried out. The test results demonstrated that the flow time (fluidity) of cement grout is the most significant factor that determines the mechanical properties of semirigid asphalt specimens under constant condition of the open graded asphalt skeleton. For the semirigid pavement mixing proportion in the current study, it is recommended that the porosity of the open graded asphalt skeleton and flow time of cement grout should be $20 \%$ and within 12 seconds, respectively.
\end{abstract}

\section{Introduction}

Asphalt and concrete pavement is the most commonly applied pavement method worldwide and is used for a variety of applications including vehicle roads and airport pavement. Rigid pavements, which mainly use concrete, are highly resistant to traffic load, have a high bearing capacity, offer long-term durability, and resist fatigue and deformation $[1,2]$. In asphalt pavement, there is excellent deformation compatibility for expansion and shrinkage with both leading to lower maintenance cost than concrete pavement [36]. These two types of pavement methods generally have opposite characteristics and are selectively applied according to environmental conditions such as external load and soil profiles. On the other hand, semirigid pavement, which can complement the advantages and disadvantages of asphalt and concrete pavement, has been studied [7-9] by a number of researchers since it was first applied to airport pavement in France [10]. In Korea, semirigid pavement has been studied since 2001 and various studies $[11,12]$ have been conducted to improve its performance. Based on these studies, semirigid pavement has been recently adopted for many construction members such as bridge-decks surfacing pavement, petrol station and heavy distribution centers. Semirigid pavement is a pavement method in which a cement grout having a relatively high stiffness and strength is filled with the skeleton of an asphalt mixture which contains $20 \sim 30 \%$ voids. The most significant characteristic of semirigid pavement is its ability to combine the ductility of asphalt and the stiffness and strength of concrete to provide excellent running performance and durability. In addition, it can be produced with various properties depending on the characteristics of the cement grouts and the skeleton of the asphalt mixture. In the current study, the physical properties of semirigid pavement were 
TABLE 1: Properties of polyacrylate polymer.

\begin{tabular}{lcccccc}
\hline Material & Density $\left(\mathrm{g} / \mathrm{cm}^{3}\right)$ & Solid contents $(\%)$ & Viscosity $(\mathrm{cps})$ & Ionicity & $\mathrm{pH}$ & Appearance \\
\hline Polyacrylate polymer & 1.0 & 45.3 & 360 & Anionic & 8.5 & White liquid \\
\hline
\end{tabular}

TABLE 2: Mixing proportions according to different types of ultrarapid hardening cement grout.

\begin{tabular}{lccccccc}
\hline \multirow{2}{*}{ Mix. } & \multirow{2}{*}{ Cement types } & \multicolumn{3}{c}{ Blending proportions (wt.\%) } & \multicolumn{3}{c}{${\text { Unit weight }\left(\mathrm{kg} / \mathrm{m}^{3}\right)}^{2}$} \\
& & Cement minerals & Accelerating agent & Retarding agent & Cement & Water & Polyacrylate polymer \\
\hline PG-1 & Proto & 46.9 & 53 & 0.1 & 1,150 & 319.5 & 255.5 \\
SG-1 & Early & 39.9 & 60 & 0.1 & 1,150 & 319.5 & 255.5 \\
& Strength & & 60 & 0.2 & 1,150 & 319.5 & 255.5 \\
FG-1 & Retarding & 39.8 & 60 & 0.3 & 1,150 & 319.5 & 255.5 \\
FG-2 & Strength & 39.7 & &
\end{tabular}

TABLE 3: Characteristics of polymer modified asphalt binder.

\begin{tabular}{lcc}
\hline Properties & Value & Standard \\
\hline Penetration at $25^{\circ} \mathrm{C}(1 / 10 \mathrm{~mm})$ & 70 & - \\
Softening point $\left({ }^{\circ} \mathrm{C}\right)$ & 72.4 & - \\
Flash point $\left({ }^{\circ} \mathrm{C}\right)$ & 362 & $\geq 230$ \\
Viscosity $(\mathrm{cp})$ & 2001 & $\leq 3,000$ \\
Density at $15^{\circ} \mathrm{C}\left(\mathrm{g} / \mathrm{cm}^{3}\right)$ & 1.028 & - \\
Storage stability $\left({ }^{\circ} \mathrm{C}\right)$ & 0.5 & $\leq 2.0$ \\
\hline
\end{tabular}

evaluated using a cement grout formulated with ultrarapid hardening characteristics. This paper includes the results of a laboratory investigation into the properties of void content, Marshal stability, flexural strength, and wheel tracking resistance depending on flow time and compressive strength of the cement grout mixed with ultrarapid hardening cement and chemical admixtures including accelerating agent and retarding agent.

\section{Materials}

2.1. Cement Grout. Four types of cement grout mixture proportions depending on the type of ultrarapid hardening cement were developed and tested. Three types of ultrarapid hardening cement including prototype, early strength type, and two kinds of retarding strength type were designed. The ultrarapid hardening cement was produced by blending cement minerals including alite $\left(\mathrm{C}_{3} \mathrm{~S}\right)$, microsilica $\left(\mathrm{SiO}_{2}\right)$, and gypsum and chemical admixtures such as accelerating agent and retarding agent. In addition, all cement grout mixtures incorporated liquid polyacrylate polymer as seen in Table 1 for the purpose of preventing cracks and shrinkage. An overview of the various mixture proportions is presented in Table 2. The fresh cement grouts were produced by using a stand mixer which was able to control mixing speed to 750 RPM. This mixing process was carried out under temperature and relative humidity conditions of $20^{\circ} \mathrm{C}$ and $60 \%$, respectively.

\subsection{Maternal Open Graded Asphalt Mixture}

2.2.1. Asphalt Binder. For mixing the open graded asphalt mixture, a polymer modified asphalt (PMA) with $4.0 \mathrm{wt} \%$ styrene butadiene styrene (SBS) was used in this study. The molecular structure of SBS is linear. The PMA commercial product type of PG 76-22 was manufactured by a domestic company in Korea and met the quality requirements for open graded asphalt mixture. The characteristics of PMA were measured based on the testing regulations and the results were listed in Table 3.

2.2.2. Aggregates and Filler. The impregnation characteristics of cement grouts into the asphalt skeleton were directly affected by its fluidity as well as by the porosity of the open graded asphalt mixture. A high porosity asphalt mixture enhanced the filling efficiency of cement grouts; however, having the appropriate porosity of asphalt mixture is significant for the strength requirements. In order to design the porosity of the open graded asphalt mixture, it is important that the application of coarse and fine aggregates satisfies the grading requirements of the specification. Fine and coarse aggregates used to accomplish this study were sourced from Gong-ju, Korea. Two types of $0.08-5 \mathrm{~mm}$ and $5-13 \mathrm{~mm}$ crushed granite gravels were selected as aggregates. All mixtures incorporated limestone powder filler with a range of $0.08-0.15 \mathrm{~mm}$. To achieve the target porosity of open graded asphalt mixture in this investigation, coarse, fine aggregates 


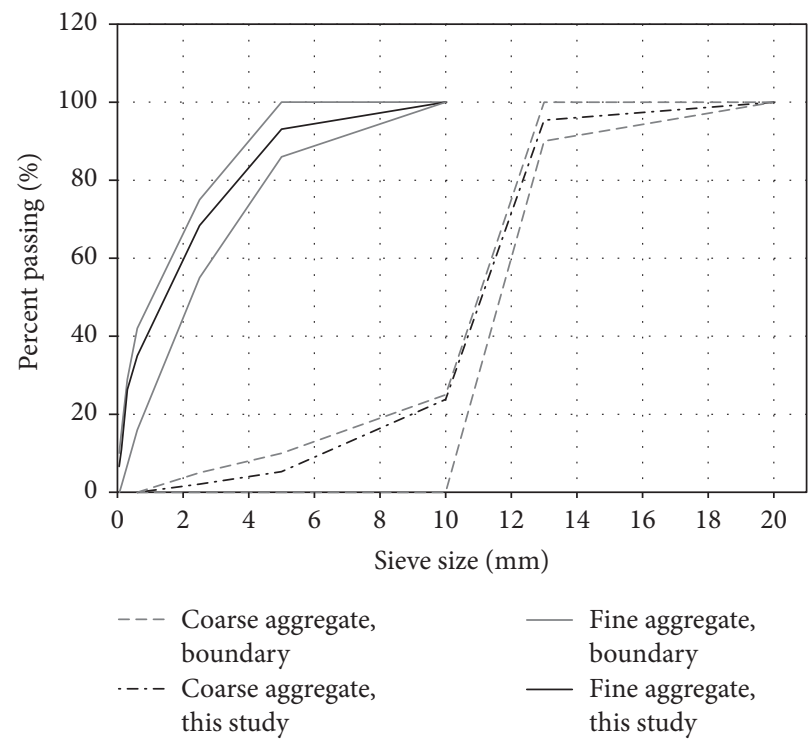

(a)

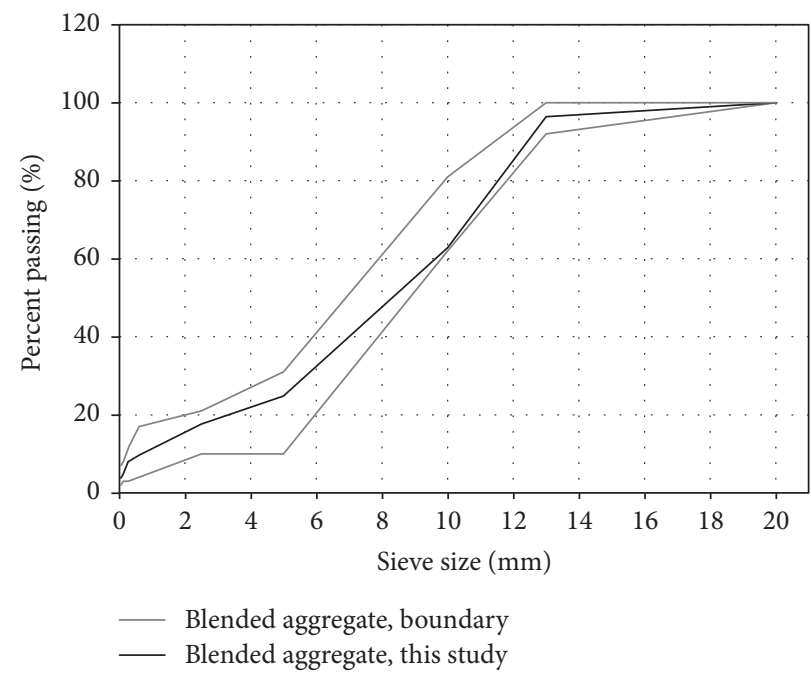

(b)

FIGURE 1: Size distribution and boundary limits of aggregates according to specification. (a) Fine and coarse aggregate grading curve. (b) Blended aggregates grading curve.

and filler were blended in accordance with the following equation:

$$
\begin{aligned}
P(i)= & A(i) \times a+B(i) \times b+C(i) \times c+\cdots+N(i) \\
& \times n .
\end{aligned}
$$

In this formula, $P(i)$ refers to the percentage of blended aggregates passing through the corresponding $(i)$ sieve, $(i)$ refers to the sieve size, $A(i), B(i), \ldots, N(i)$ refer to the percentage of each aggregate passing through the corresponding $(i)$ sieve, $A, B, \ldots, N$ refer to all kinds of aggregate and filler, and $a, b, \ldots, n$ refer to the contents proportion of each aggregate and filler, and the sum total is $100 \%$. The grading curve of all types of aggregates used has been made to meet the open graded asphalt grading requirements of the Korean standard specification as shown in Figure 1(a). The Korean standard specification suggests the boundary limits for the blended aggregates and filler used for the open graded asphalt mixture as shown in Figure 1(b). The mechanical properties of fine aggregate, including density, water absorption, and fineness modulus, are $2.66 \mathrm{~g} / \mathrm{cm}^{3}, 0.9 \%$, and 3.02 , while for coarse aggregate they are $2.67 \mathrm{~g} / \mathrm{cm}^{3}, 0.9 \%$, and 6.08 , respectively. Water content and density of limestone filler were measured as $0.2 \%$ and $2.72 \mathrm{~g} / \mathrm{cm}^{3}$.

2.2.3. Mixing Open Graded Asphalt. Based on the previous studies [10] and the Korean standard of open graded asphalt mixture design [13], the porosity of asphalt mixture is designed with a range of $18 \sim 22 \%$. The dosage of asphalt is $3.5 \% \sim 6.0 \%$. The open graded asphalt mixture proportions are presented in Table 2. In order to mix the open graded asphalt mixtures, all aggregates are cleaned and kept preheated to a temperature of $120^{\circ} \mathrm{C}$ to $150^{\circ} \mathrm{C}$, while asphalt was heated to a temperature of $150^{\circ} \mathrm{C}$. All specimens are cast into the molds and compacted under hot condition according to the experiment standards. All specimens are taken out from the mold when the temperature of specimens reached $50^{\circ} \mathrm{C}$.

2.2.4. Semirigid Asphalt Composite. Open graded asphalt mixtures were prepared according to the experimental method of Korea standards and four types of cement grout were injected and compacted. After that, all semirigid asphalt specimens were cured until standardized curing age.

\section{Test Program}

\subsection{Cement Grout}

3.1.1. Fluidity. The flow cone test has been carried out to evaluate the fresh fluidity of cement grout. The flow cone used in this study is for the hydraulic cement grout flow test regulated in KS F 4044 method. It has a height of $190 \mathrm{~mm}$, a capacity of $1725 \pm 5 \mathrm{~mL}$, and an internal orifice diameter of $12.7 \mathrm{~mm}$. All the grouts were charged to the calibration height and the dropping time was measured. Flow time is an index of the fluidity of the cement grout. Figure 2 shows the geometry of the flow cone used in this study. In the previous study [14] the flow time of the flow cone with a capacity of $1,200 \mathrm{~mL}$ and an internal orifice diameter of $10 \mathrm{~mm}$ was measured from 11 to 20 seconds. Lei [15] reported that, for the cone with a capacity of $1,000 \mathrm{~mL}$ and an internal orifice diameter of $10 \mathrm{~mm}$, flow time was proposed to be in the range of 8 to 10 seconds. Also, because the flow value is slightly different depending on the cone size in the previous studies $[16,17]$ the flow value of this study can be used for a relative comparison of the grout formulations. 


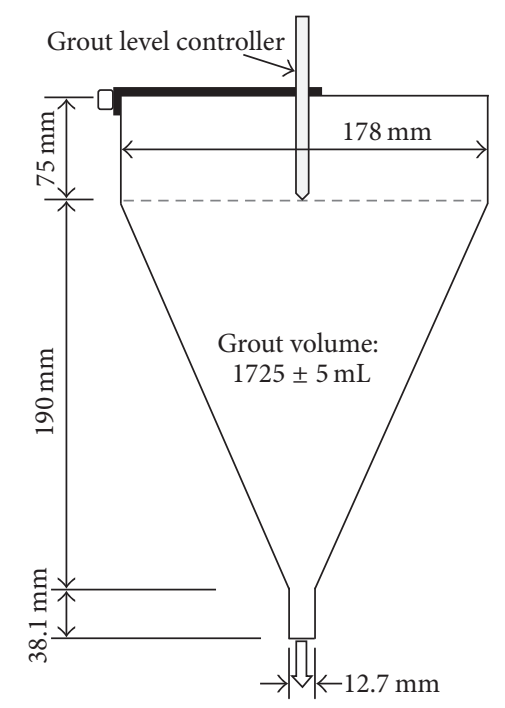

FIGURE 2: Flow cone geometry for hydraulic cement grout flow test.

3.1.2. Compressive Strength. A total of sixty cubic $50 \times 50 \mathrm{~mm}$ specimens for the compressive strength test were fabricated and cured under standard conditions. The compressive strength test was carried out using a universal test machine with a capacity of $500 \mathrm{kN}$, and loading rate was controlled to $2.4 \mathrm{kN} / \mathrm{sec}$. The compressive strength was calculated based on the average of three specimens.

\subsection{Semirigid Asphalt Composite}

3.2.1. Porosity. The open graded asphalt specimens were filled with asphalt mixture of $1,200 \mathrm{~g}$ in a mold with a diameter of $101.6 \mathrm{~mm}$ and a height of $63.5 \mathrm{~mm}$, and the compaction hammer was freely dropped from a height of $450 \mathrm{~mm}$ to compact 50 times on each surface, respectively. The specimens were coated with paraffin due to the fact that the moisture content of all specimens exceeded $2 \%$. The porosity test was performed in accordance with KS F 2353 and ASTM D 1188. First of all, specific bulk density $\left(\gamma_{\text {bulk }}\right)$ of all the specimens was calculated using (2). On the other hand, the theoretical maximum density $\left(\gamma_{\text {theoretical }}\right)$ of the specimen, which can be compared with the apparent density, was calculated based on (3) using an automatic device of theoretical maximum density in order to quantify the effect of the grain size, the asphalt content, and the temperature condition. The porosity of all specimens including open graded asphalt mixtures and semirigid asphalt mixtures is given in (4).

$$
\begin{aligned}
& \text { Specific bulk density }\left(\gamma_{\text {bulk }}\right) \\
& =\frac{P_{\text {air }}}{P_{\mathrm{pa}}-P_{\mathrm{wa}}-\left(P_{\mathrm{pa}}-P_{\text {air }}\right) / r_{\mathrm{pa}}},
\end{aligned}
$$

Theoretical maximum density $\left(r_{\text {theoretical }}\right)$

$$
\begin{gathered}
=\frac{P_{\text {air }}}{P_{\text {air }}+P_{\text {bowl }}-P_{\text {all }}}, \\
\text { Porosity }(\%)=\left[1-\frac{\gamma_{\text {bulk }}}{\gamma_{\text {theoretical }}}\right] \times 100,
\end{gathered}
$$

where, $P_{\text {air }}$ is dry weight of specimen in air $(\mathrm{g}), P_{\mathrm{pa}}$ is paraffin coated dry weight of specimen in air $(\mathrm{g}), P_{\mathrm{wa}}$ is paraffin coated dry weight of specimen in water $(\mathrm{g}), r_{\mathrm{pa}}$ is bulk density of paraffin $\left(\mathrm{g} / \mathrm{cm}^{3}\right), P_{\text {bowl }}$ is weight of bowl filled with water at $25^{\circ} \mathrm{C}(\mathrm{g})$, and $P_{\text {all }}$ is weight of bowl filled with water and specimen at $25^{\circ} \mathrm{C}(\mathrm{g})$.

3.2.2. Marshall Stability. For the Marshall stability test, the specimen was fabricated in the same shape and method as the specimen prepared for the porosity test. The fabricated asphalt mixture specimens were cooled at room temperature for five hours and taken out from the mold using a sample extractor. After that, cement grout was injected and cured at a room temperature of $20^{\circ} \mathrm{C}$ for 1 day. All the semirigid asphalt specimens were tested using Marshall stability equipment. The test was carried out at a constant loading rate of $50 \mathrm{~mm} / \mathrm{min}$ until failure in accordance with the KS F 2337 standard. The measured maximum vertical load refers to the Marshall stability value.

3.2.3. Wheel Tracking. For the wheel tracking test regulated by KS F 2374, the asphalt mixture was filled in a square mold having a length $\times$ width $\times$ height of $300 \mathrm{~mm} \times 300 \mathrm{~mm} \times$ $50 \mathrm{~mm}$, and a specimen was prepared by using a compaction roller of which surface temperature was kept at $130^{\circ} \mathrm{C}$. After demolding, cement grout was injected and cured at a room temperature of $20^{\circ} \mathrm{C}$ for 1 day. The wheel tracking test was carried out by placing each specimen in a chamber maintained at a temperature of $60^{\circ} \mathrm{C}$ for 5 hours so that the test can be carried out under the same temperature conditions for all specimens. The chamber was equipped with steel wheel tires with a diameter of $200 \mathrm{~mm}$ and a width of $50 \mathrm{~mm}$. The wheel was attached with rubber with a thickness of $15 \mathrm{~mm}$ to simulate the wheel of the rear vehicle. The wheel consisted of a vertical loading device and a horizontal moving device. The vertical device applies a load continuously at $686 \mathrm{~N}$ and the horizontal device performs a horizontal reciprocating run at a 
speed of $0.5 \mathrm{~Hz}$ (30times/min.) for a maximum runway distance of $300 \mathrm{~mm}$ for 1 hour. The central deflection of the specimen was measured at 5-minute intervals using LVDT with resolution capacity of $1 / 100 \mathrm{~mm}$ attached on the wheel device. In particular, the dynamic stability represents the number of reciprocating runs required for $1.0 \mathrm{~mm}$ deflection at the center of the wheel tracking specimen and is calculated using (5) below. The deformation rate $(\mathrm{mm} / \mathrm{min}$.) was calculated between 45 and 60 minutes.

$$
\mathrm{DS}=42 \times \frac{t_{2}-t_{1}}{d_{2}-d_{1}}
$$

where DS is the dynamic stability, $d_{1}$ refers to the central deflection at 45 minutes $\left(t_{1}\right)$, and $d_{2}$ refers to the deflection at 60 minutes $\left(t_{2}\right)$.

3.2.4. Flexural Strength. The bending specimen was prepared by dividing the wheel tracking specimen into three equal parts. The shape of the specimen is length $(l) \times$ width $(b) \times$ height $(h)$ of $300 \mathrm{~mm} \times 100 \mathrm{~mm} \times 50 \mathrm{~mm}$. After allowing all the specimens to air dry, all specimens were put in a constant temperature chamber set at $-10^{\circ} \mathrm{C}$ for 1 day in order to maintain the specimen temperature in the same condition. The test was carried out while maintaining a constant room temperature of $20^{\circ} \mathrm{C}$. In order to prevent the abrupt failure of the specimen, the one-point load was continuously applied to the center of the specimen at a speed of $0.5 \mathrm{~mm} / \mathrm{min}$ using the displacement control method. The applied load $(P)$ and central displacement $(d)$ of the specimen were measured at load cell with capacity of $50 \mathrm{kN}$ and a linear variable displacement transducer (LVDT) with capacity of $10 \mathrm{~mm}$ was used to measure the applied load corresponding to the central displacement of the specimen. All the specimens were tested until the load was $0 \mathrm{~N}$, and all data was saved in the TDS-530 data logger. The maximum flexural strength and corresponding flexural strain can be calculated using (6) and (7), respectively.

$$
\begin{aligned}
\text { Flexural strength }\left(f_{r}\right) & =\frac{3 l P}{2 b h^{2}}, \\
\text { Flexural strain }(\varepsilon) & =\frac{6 h d}{l^{2}} .
\end{aligned}
$$

\section{Results and Discussion}

\subsection{Cement Grout}

4.1.1. Fluidity. The flow time results in accordance with the ratio of accelerating and retarding agent content are shown in Figure 3. The flow time of PG-1 mixture was measured to be 10.5 s. For SG-1, FG-1, and FG-2, which were mixed with accelerating agent, it was measured as $12.8 \mathrm{~s}, 11.3 \mathrm{~s}$, and $10.9 \mathrm{~s}$, respectively. The use of accelerating agent increased the flow time of cement grout compared to the PG-1 mixture by $22 \%$, $10 \%$, and $4 \%$, respectively. However, it can be seen that, with the same dosage of the accelerating agent, the flow time decreases as the amount of retarding agent used increases. The flow times of FG-1 and FG-2 mixtures were $91 \%$ and $85 \%$,



FIGURE 3: Flow time according to the cement grout mixtures.

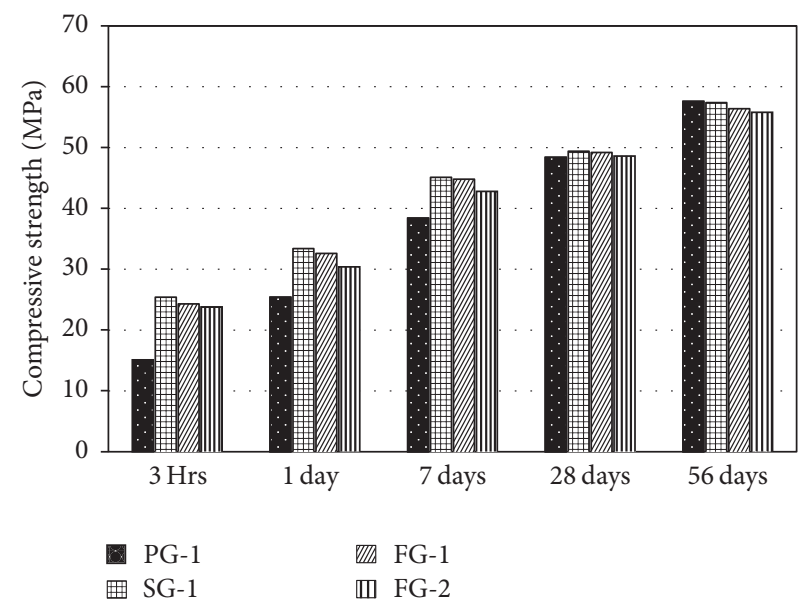

FIGURE 4: Compressive strength results of cement grout mixtures.

respectively, compared with the SG-1 mixture. Therefore, in order to secure the rapid hydration of the cement grout, it was shown that the use of the retarding agent can control the fluidity sufficiently when the accelerating agent was incorporated into the cement grout. Since the cement grout plays an important role in filling the pores of the open graded asphalt mixture to form a semirigid pavement, it should have sufficient fluidity to fill the pores. Afonso et al. [14] reported a flow time of $11 \mathrm{~s}$ to $20 \mathrm{~s}$ for a cone with a capacity of $1,200 \mathrm{~mL}$ and an internal orifice diameter of $10 \mathrm{~mm}$. Lei has proposed a cone with a capacity of $1,000 \mathrm{~mL}$ and an internal orifice diameter of $10 \mathrm{~mm}$ within a range of $8 \mathrm{~s}$ to $10 \mathrm{~s}$. Because the flow time differed according to the cone size in the previous study, the flow value in this current study was able to be used for relative comparisons of cement grout mixtures.

4.1.2. Compressive Strength. The findings related to compressive strength of all cement grout mixtures are presented in Figure 4. For all cement grouts using ultrarapid hardening cement, it was clear that the compressive strength exceeded $15 \mathrm{MPa}$ for 3 hours. Compressive strength of SG-1, FG-1, and FG-2 mixtures that incorporated accelerating agent was $168 \%, 161 \%$, and $158 \%$ higher, respectively, than that of the PG-1 mixture for 3 hours. As the amount of retarding agent 


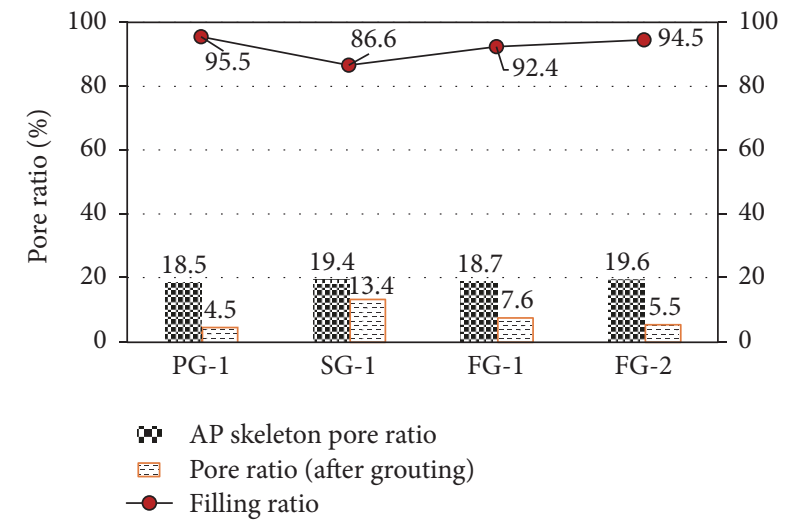

(a)

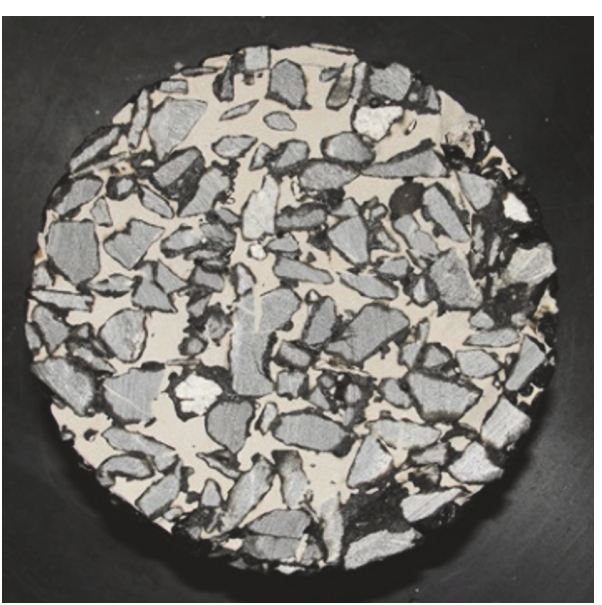

(b)

FIGURE 5: Pore ratio results of semirigid asphalt specimens. (a) Pore ratio results of semirigid asphalt specimens. (b) Specimen for porosity test.

dosage increased from $0.1 \%$ to $0.3 \%$, the compressive strength at early-age including 3 hours and 1 day tended to decrease when the mixing content of accelerating agent was fixed in the cement grout mixture. It can be seen in Figure 4, however, that the compressive strength of all cement grout mixtures can be maintained at a similar level in long-term ages. The use of retarding agents is expected to have a positive effect on the increase of the fluidity of the initial cement grout and is not significantly affected by the reduction of compressive strength in all ages.

\subsection{Semirigid Asphalt Composite}

4.2.1. Porosity. The pore ratio and filling ratio of the open graded asphalt skeleton and the semirigid asphalt specimens filled with four types of cement grout mixture are shown in Figure 5(a), and the FG-1 specimen for porosity test is represented in Figure 5(b). From the porosity test, the average porosity of four specimens for each open graded asphalt skeleton was evaluated as $19.1 \%$, with porosity being in a range of $18.5 \%$ to $19.6 \%$. After filling cement grout into the open graded asphalt skeleton, the porosity of the PG-1, SG-1, FG1 , and FG-2 specimens was measured as $4.5 \%, 13.4 \%, 7.6 \%$, and $5.5 \%$, and, using (2), the filling ratios of the cement grout mixtures were calculated as $95.5 \%, 86.6 \%, 92.4 \%$, and $94.5 \%$, respectively. As can be seen from Figures 3 and 5, a flow time of cement grout mixtures within $12 \mathrm{~s}$ enabled an excellent filling ratio over $90 \%$ to be secured. These results indicated that the flow time, which is a typical index of fluidity, has a strong influence on the filling rate of the semirigid asphalt pavement given similar porosity condition of the open graded asphalt skeleton. In this current study, PG-1, FG-1, and FG-2 are suitable cement grout proportions for semirigid pavement that could secure outstanding filling property.

4.2.2. Marshall Stability. The results of the Marshall stability test were shown in Figure 6. In the open graded asphalt skeleton, the Marshall stability of the specimens was measured as
$5.43 \sim 5.82 \mathrm{kN}$ and the average value was calculated as $5.68 \mathrm{kN}$. Semirigid pavement mixtures such as PG-1, SG-1, FG-1, and FG-2 filled with cement grout exhibited outstanding Marshall stability. The average value is $430 \%, 374 \%, 404 \%$, and $413 \%$ higher than that of skeleton mixture, respectively, and the semirigid pavement specimens showed very stable results after grouting. On the other hand, although the compressive strength of the SG-1 for 1 day was the highest among all cement grout mixtures, the Marshall stability value of the SG1 was $86.9 \%, 92.5 \%$, and $90.5 \%$ that of the PG-1, FG-1, and FG-2 mixtures, respectively. From the test results, it can be inferred that the Marshall stability of the semirigid pavement was strongly dependent on the fluidity of the cement grout rather than the strength of the cement grout. Meanwhile, the relationship between Marshall stability and filling ratio of all semirigid pavement specimens is shown in Figure 7. Marshall stability was found to increase linearly as the filling ratio increased, and the correlation coefficient was calculated as $92 \%$. This result indirectly shows that the filling degree of the cement grout in the pores of asphalt skeleton determines the level of Marshall stability performance.

4.2.3. Flexural Strength. Figure 8 presents the flexural strength and midspan deflection relation curve of the asphalt skeleton and semirigid pavement specimens. The flexural strength of open graded asphalt skeleton and correlating flexural strain were calculated as $0.64 \mathrm{MPa}$ and $0.524 \%$, respectively. The flexural strength of PG-1, SG-1, FG-1, and FG-2 was calculated as $3.21 \mathrm{MPa}, 2.92 \mathrm{MPa}, 3.18 \mathrm{MPa}$, and $3.10 \mathrm{MPa}$, and corresponding flexural strain was $0.212 \%$, $0.210 \%, 0.237 \%$, and $0.247 \%$, respectively. The test results were listed in Table 4 . It was found that the semirigid pavement specimens were able to improve the flexural strength of asphalt skeleton by at least $453 \%$ and by up to $498 \%$, and the flexural strain corresponding to maximum flexural strength could be decreased by a range of $40.1 \%$ to $47.0 \%$. It was clearly found that the flexural strength of semirigid pavement specimens was enhanced by filling cement grout into the asphalt 
TABLE 4: Flexural test results of all specimens.

\begin{tabular}{lccc}
\hline & Flexural strength $(\mathrm{MPa})$ & Midspan deflection $(\mathrm{mm})$ & Flexural strain $(\%)$ \\
\hline Asphalt skeleton & 0.64 & 1.57 & 0.524 \\
PG-1 & 3.21 & 0.64 & 0.212 \\
SG-1 & 2.92 & 0.63 & 0.211 \\
FG-1 & 3.18 & 0.71 & 0.237 \\
FG-2 & 3.10 & 0.74 & 0.247 \\
\hline
\end{tabular}

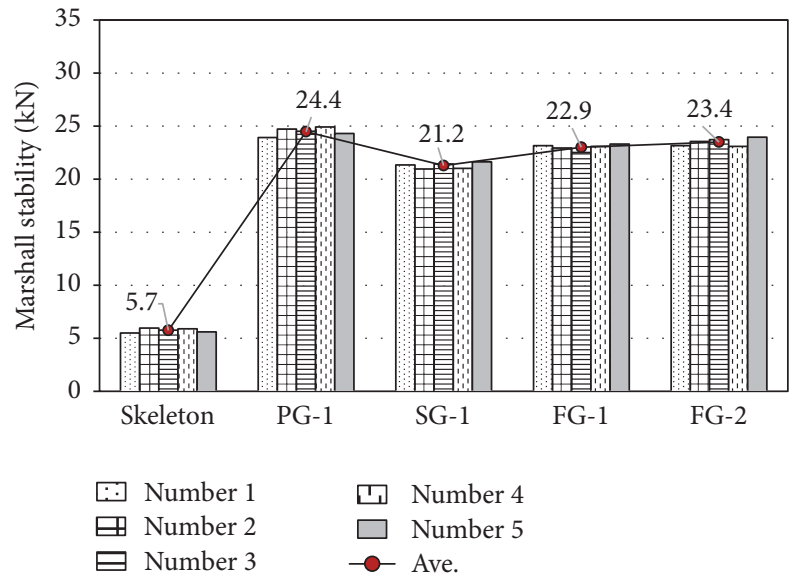

FIgURE 6: Results of Marshall stability test.

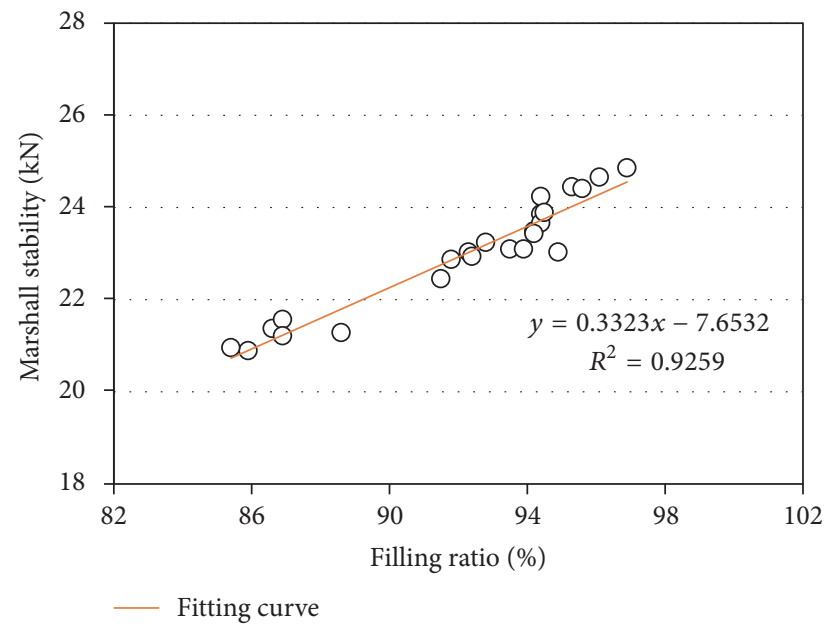

FIGURE 7: Relationship between Marshall stability and filling ratio of all semirigid pavement specimens.

skeleton. However, as expected, the lowest fluidity of the SG-1 cement grout mixture was measured as $2.92 \mathrm{MPa}$, and the other three types of semirigid pavement specimens with a similar level of fluidity showed no significant difference according to the type of cement grout. Similarly to the results of Marshall stability, the flexural strength was also significantly affected by the fluidity of the cement grout filled in the asphalt skeleton pores. From the flexural test results, it was found that the semirigid pavement could strongly

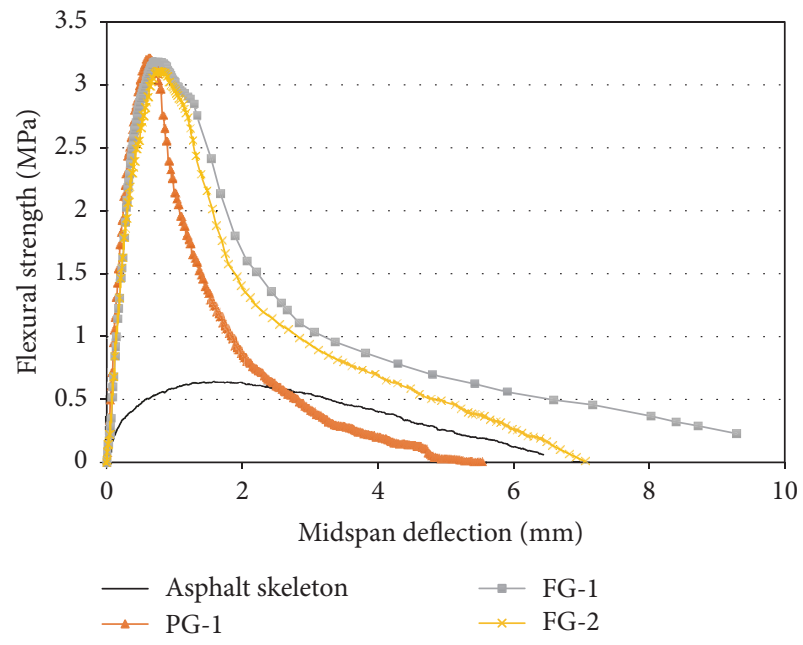

FIGURE 8: Results of flexural test of asphalt skeleton and semirigid asphalt specimens.

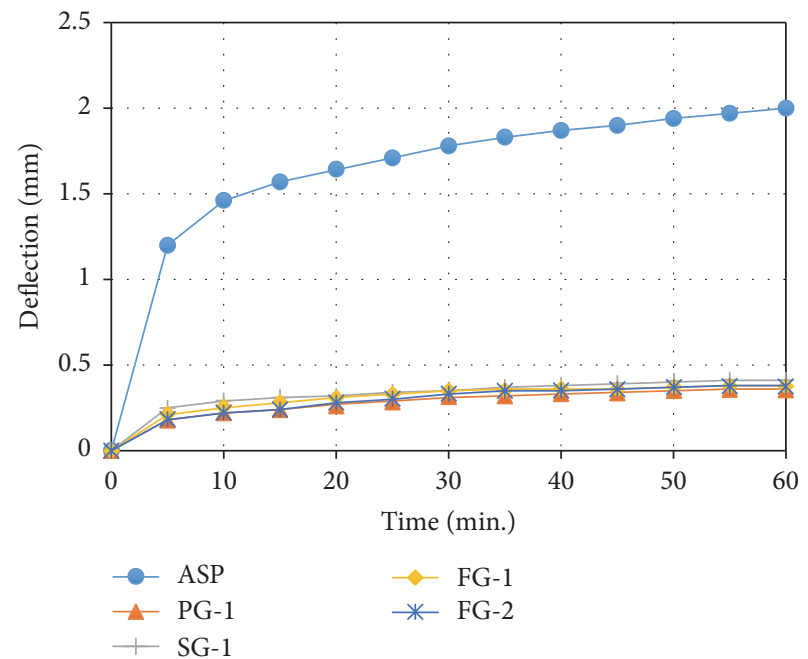

FIGURE 9: Results of wheel tracking test of asphalt skeleton and semirigid asphalt specimens.

enhance the low stiffness of the open graded asphalt skeleton with flexural strength.

4.2.4. Wheel Tracking Resistance. The relationship between the vertical loading and correlating central deflection measured by the wheel tracking test is shown in Figure 9. In 
the open graded asphalt skeleton, the initial center deflection rapidly increased to $1.2 \mathrm{~mm}$ by $5 \mathrm{~min}$. For semirigid pavement specimens such as PG-1, SG-1, FG-1, and FG-2 mixtures, however, it was found that the initial deflection at the center was $0.18 \mathrm{~mm}, 0.25 \mathrm{~mm}, 0.21 \mathrm{~mm}$, and $0.18 \mathrm{~mm}$. These values range from 4.8 times to 6.7 times lower than that of the open graded asphalt skeleton. This result shows that cement grouting is effective in controlling the initial deformation for the open graded asphalt skeleton. As can be seen from the graph slope in Figure 9, the deflection of the asphalt skeleton was continuously increased until the end of the experiment. For the semirigid pavement specimens, however, the center deflection gradually increased and then converged after 40 minutes. It was found that the final deflection of the open graded asphalt skeleton specimen was the largest at $2.0 \mathrm{~mm}$, but it was $0.36 \mathrm{~mm}$ to $0.41 \mathrm{~mm}$ for semirigid pavement, which could reduce the final deflection by at least 4.88 times compared to the asphalt skeleton. The dynamic stability of all the semirigid pavement specimens was calculated as 31,500 times $/ \mathrm{mm}$, while for the asphalt skeleton it was 6,300 times $/ \mathrm{mm}$. In addition, the deformation rate of semirigid pavement specimens was $0.0013 \mathrm{~mm} / \mathrm{min}$ compared with $0.0067 \mathrm{~mm} / \mathrm{min}$ of the asphalt skeleton. The test results show that it was possible to effectively enhance the dynamic stability and deformation rate for deformation, thereby improving the durability of asphalt pavement under repeated vehicle load.

\section{Conclusions}

This current study investigated the effect of cement grout controlled with ultrarapid hardening cement, accelerating and retarding chemical agent on the mechanical properties of semirigid pavement. In the first stage of this study, the effect of chemical admixtures on the cement grout fluidity and compressive strength was evaluated. In the next stage, the open graded asphalt pavement mixture, which is the skeleton of the semirigid pavement, was designed to have a porosity of $18 \sim 20 \%$. Finally, semirigid pavement specimens were prepared by injecting cement grout into an open graded asphalt pavement. Mechanical properties including porosity, flexural strength, Marshall stability, and wheel tracking resistance were evaluated. From the test results it was clearly found that the porosity and filling rate of semirigid pavement specimens were greatly influenced by the flow time (fluidity) of cement grout. The use of chemical admixtures was found to be able to control the initial flow time; the compressive strength property, however, was not significantly affected. Through evaluating the strength characteristics through Marshall stability, flexural strength, and wheel tracking test, it was found that the fluidity favorable to filling of the cement grout in the voids of asphalt skeleton greatly influences the strength of semirigid pavement rather than the cement grout compressive strength property. Semirigid pavement could improve the strength and stiffness of open graded asphalt mixture, and the semirigid pavement's performance could be adjusted to the target performance by controlling the flow and strength characteristics of the cement grout. Based on the test results, it was recommended that the porosity of open graded asphalt be $20 \%$ and the flow time of cement grout be within 12 seconds.

\section{Conflicts of Interest}

The authors declare that there are no conflicts of interest regarding the publication of this article.

\section{Acknowledgments}

This research was supported by Basic Science Research Program through the National Research Foundation of Korea (NRF) funded by the Ministry of Science, ICT \& Future Planning (no. 2016R1A2B4011810).

\section{References}

[1] P. Saxena and L. Khazanovich, "Determination of critical bending stresses in portland cement concrete layer with asphalt overlay," Transportation Research Record, vol. 2306, 2013.

[2] Y.-H. Cho, H. Chiu, and B. F. McCullough, "Asphalt overlay design methods for rigid pavements considering rutting, reflection cracking, and fatigue cracking," Tech. Rep., Center for Transportation Research, The University of Texas, Austin, Tex, USA, 1998.

[3] M. Dinis-Almeida, J. Castro-Gomes, M. L. Antunes, and L. Vieira, "Mix design and performance of warm-mix recycled asphalt," Proceedings of Institution of Civil Engineers-Construction Materials, vol. 167, no. 4, pp. 173-181, 2013.

[4] N. Kawamura, Y. Morikawa, M. Murayama, T. Hirato, and R. Maekawa, "Durability of high-stability asphalt mixture under aircraft loading," in Proceedings of the 2014 FAA Worldwide Airport Technology Transfer Conference, pp. 1-14, Galloway, NJ, USA, 2014.

[5] C.-T. Chiu, T.-H. Hsu, and W.-F. Yang, "Life cycle assessment on using recycled materials for rehabilitating asphalt pavements," Resources, Conservation and Recycling, vol. 52, no. 3, pp. 545556, 2008.

[6] A. Setyawan, "Asessing the compressive strength properties of semi-flexible pavements," in Proceedings of the 2nd International Conference on Rehabilitation and Maintenance in Civil Engineering, ICRMCE 2012, vol. 54, pp. 863-874, Indonesia, 2013.

[7] K. E. Hassan, A. Setyawan, and S. E. Zoorob, "Effect of cementitious grouts on the properties of semi-flexible bituminous pavement," in Proceedings of the Fourth European Symposium on Performance of Bituminous and Hydraulic Materials in Pavement, pp. 113-120, Nottingham, UK, 2002.

[8] S. Koting, M. R. Karim, H. B. Mahmud, and N. A. A. Hamid, "Mechanical properties of cement-bitumen composites for semi-flexible pavement surfacing," The Baltic Journal of Road and Bridge Engineering, vol. 9, no. 3, pp. 191-199, 2014.

[9] S. Li, X. Liu, and Z. Liu, "Interlaminar shear fatigue and damage characteristics of asphalt layer for asphalt overlay on rigid pavement," Construction and Building Materials, vol. 68, pp. 341-347, 2014.

[10] B. Yang and X. Weng, "The influence on the durability of semiflexible airport pavement materials to cyclic wheel load test," Construction and Building Materials, vol. 98, pp. 171-175, 2015.

[11] T. S. Park, "Evaluation of the performance and moisture retaining ability in semi-rigid pavement," Journal of Korean Society of Road Engineers, vol. 10, no. 1, pp. 69-79, 2008. 
[12] J. W. Kim and K. W. Kim, "A review of long-term serviceability of semi-rigid pavement," Magazine of Korean Society of Road Engineers, vol. 12, no. 2, pp. 35-40, 2010.

[13] "Provisional guidelines for porous asphalt pavement," Provisional guidelines for Porous Asphalt Pavement, No.11-1611000001712-01, 2011.

[14] M. L. Afonso, M. Dinis-Almeida, L. A. Pereira-De-Oliveira, J. Castro-Gomes, and S. E. Zoorob, "Development of a semiflexible heavy duty pavement surfacing incorporating recycled and waste aggregates-preliminary study," Construction and Building Materials, vol. 98, pp. 171-175, 2015.

[15] W. Lei, "The design and construction of semi-rigid pavement materials in perfusion type," in Proceedings of the International Conference on Computer Distributed Control and Intelligent Environmental Monitoring, pp. 711-715, IEEE, Hunan, China, March 2012.

[16] H. Zhang, "Semi-flexible pavement with cement mortar mix design," Jilin Highway and Transportation Research, vol. 2, pp. $8-23,1999$.

[17] D. Q. Wu, Daud, and Y. Zhang, "The semi-rigid pavement with higher performances for roads and parking aprons," in Proceeding of the 29th Conference of ASEAN Federation of Engineering Organizations-Sustainable Urbanization-Engineering Challenges and Opportunities, pp. 1-7, The Rizqun International Hotel, Brunei Darussalam, November 2011. 

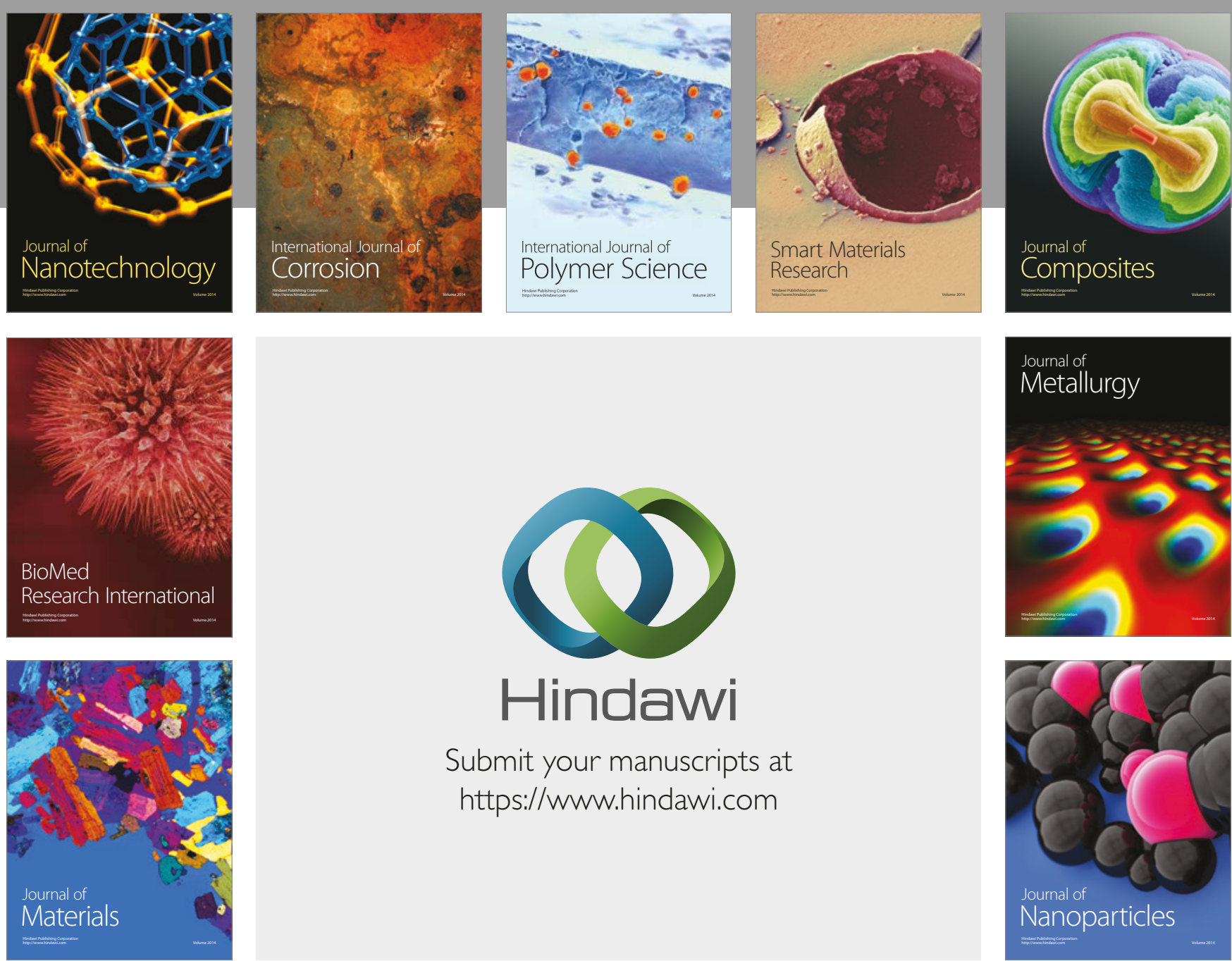

\section{Hindawi}

Submit your manuscripts at

https://www.hindawi.com
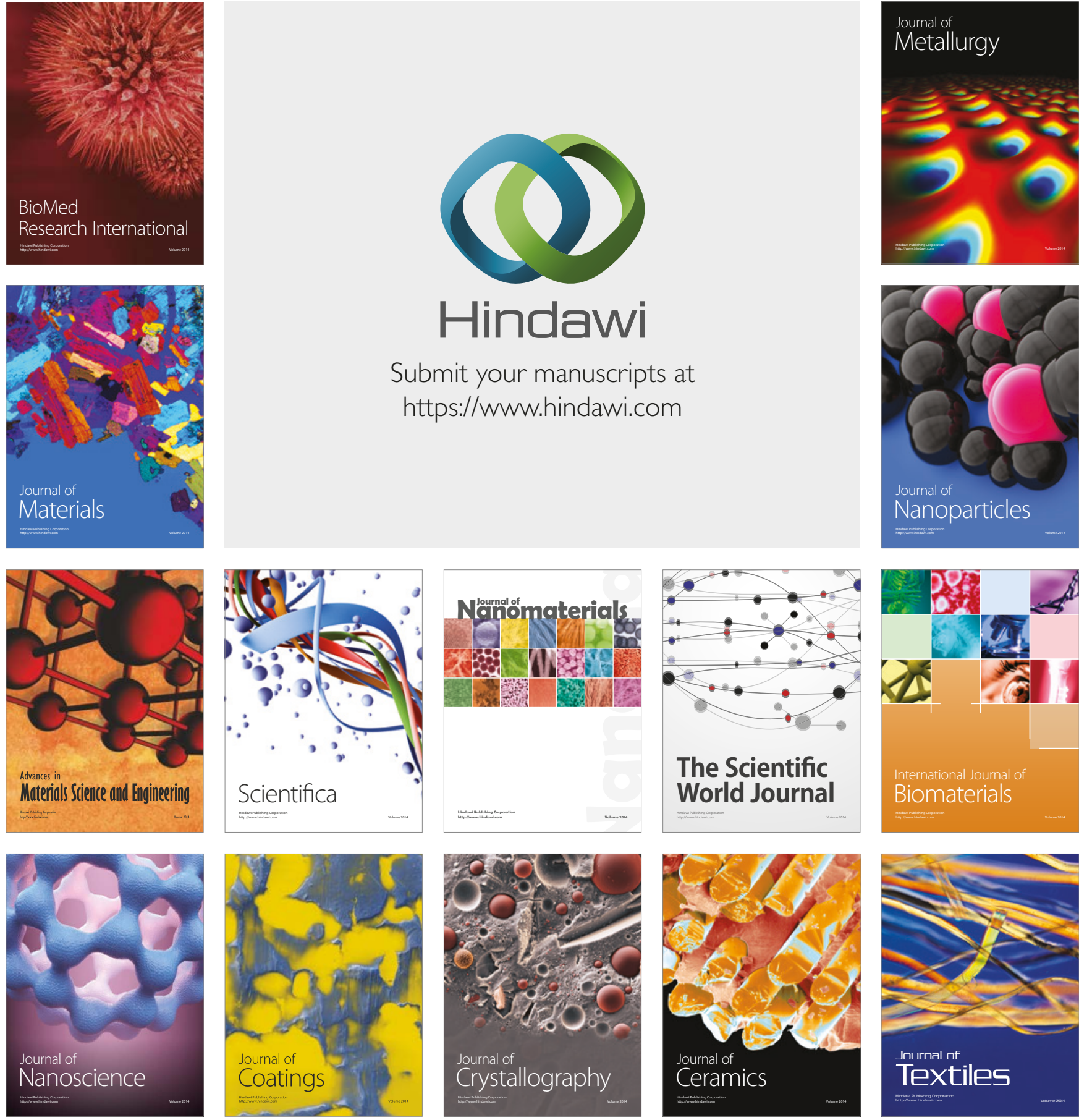

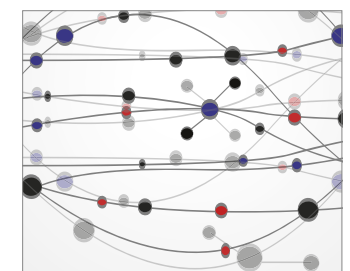

The Scientific World Journal
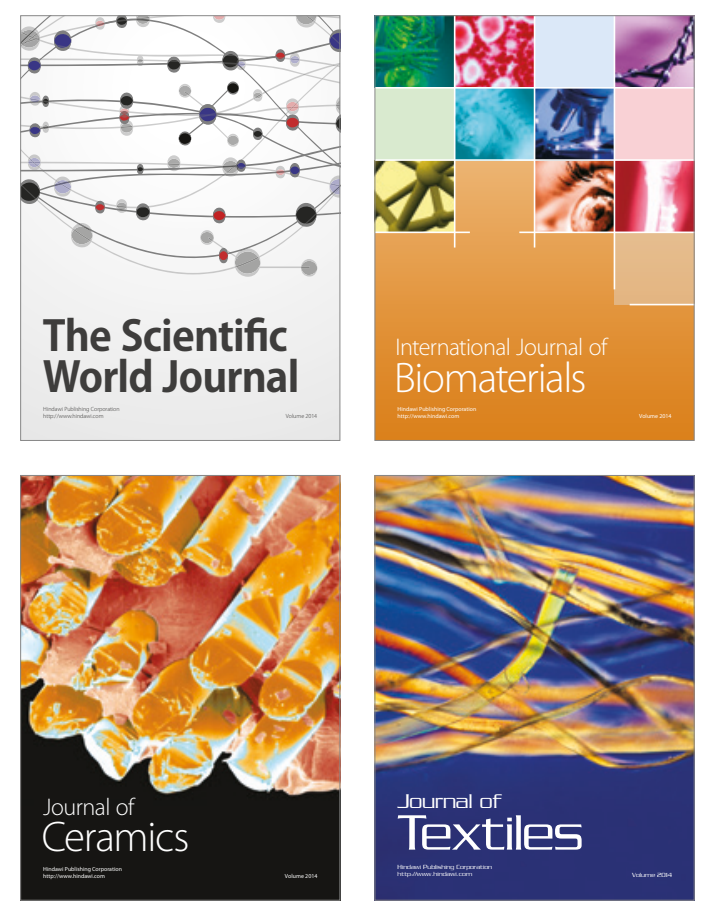